\title{
EXPANDING THE FRONTIERS OF SUCCINATE-CONTAINING DIALYSATE'S EFFECTS
}

Research Institute of Nephrology of the Pavlov First Saint-Petersburg State Medical University, Russia

\section{РЕФЕРАТ}

Сукцинат является метаболитом гипоксического стресс-сигнала. Попадая в организм больного из диализирующего раствора во время сеанса гемодиализа, сукцинат ингибирует пролилгидроксилазы, что приводит к стабилизации фактора, индуцируемого гипоксией (HIF), и к развертыванию многочисленных HIF-опосредованных эффектов. Применение сукцинатсодержащих диализирующих растворов можно рассматривать как псевдогипоксическое прекондиционирование, оказывающее благоприятное действие на ряд клинико-биохимических показателей пациентов.

Ключевые слова: сукцинат, гемодиализ, сукцинатсодержащий диализирующий раствор, фактор, индуцируемый гипоксией (HIF).

\section{ABSTRACT}

Succinate is hypoxic stress signal metabolite. Entering the patient's body from the dialysate during hemodialysis, succinate inhibits prolylhydroxylases, leading to stabilization of hypoxia-inducible factor (HIF) and to the deployment of many HIF-mediated effects. Application of succinate-containing dialysis solutions can be considered as pseudohypoxic preconditioning, which provides the beneficial effect on several clinical and biochemical parameters of patients.

Key words: succinate, hemodialysis, succinate-containing dialysate, hypoxia-inducible factor (HIF).

Опубликованная в данном номере журнала «Нефрология» статья Матеуса де Кастро Фонсеки и соавт. «GPR91: расширение представлений о метаболитах цикла Кребса» является лаконичным, но достаточно полным обзором современных знаний об эффектах стимуляции сукцинатом рецепторов GPR91 и, безусловно, заслуживает внимания читателя. Однако физиологические функции сукцината далеко не ограничиваются ролью лиганда GPR91. Поэтому кажется целесообразным дополнить картину сведениями о других биологических процессах, в которых важную роль играет сукцинат, тем более что на протяжении последних лет в НИИ нефрологии ПСПбГМУ им. И.П. Павлова были проведены ряд исследований, касающихся применения сукцинатсодержащих диализирующих растворов у больных на хроническом

Голубев Р.В. 197022, Россия, Санкт-Петербург, ул. Л. Толстого, д. 17, корп. 54. Первый Санкт-Петербургский государственный медицинский университет им. акад. И.П. Павлова, научно-исследовательский институт нефрологии. Тел. (812) 338-69-14; E-mail: romvladgol@ gmail.com гемодиализе. Некоторые результаты, полученные нами, могут послужить практическим подтверждением экспериментальных данных из литературных источников. Ввиду того, что многие аспекты биохимического действия сукцината были рассмотрены в наших предыдущих публикациях [15], в этом сообщении хотелось бы прежде всего остановиться на взаимоотношениях сукцината и фактора, индуцируемого гипоксией.

В соответствии с современными представлениями, сукцинат является метаболитом стресс-сигнала, в первую очередь - гипоксического [6-8]. Схема биохимических процессов, приводящих к увеличению продукции сукцината в условиях гипоксии, представлена в статье де Кастро Фонсеки и соавт. Данный механизм адаптации клеток к гипоксии является, по всей видимости, эволюционно древним и присутствует, к примеру, в гетеротрофных тканях растений, где при недостатке кислорода также происходит альтернативный приток метаболитов в цикл трикарбоновых кислот (ЦТК, цикл Кребса), а 
сам цикл претерпевает бифуркацию на «восстановительную» и «окислительную» части [9].

К этому необходимо добавить, что в организме человека и животных увеличение продукции сукцината в митохондриях в условиях гипоксии, вероятно, обусловлено не только частичным обращением ЦТК и неферментативным декарбоксилированием $\alpha$-кетоглутарата, но и активизацией части цикла Кребса в «прямом» направлении, а именно, стимуляцией ферментативного превращения $\alpha$-кетоглутарата в сукцинат. Как справедливо указано в статье де Кастро Фонсеки, при недостатке кислорода возникает дефицит окисленного никотинамидадениндинуклеотида $\left(\right.$ НАД $\left.^{+}\right)$, необходимого для целого ряда ключевых биохимических процессов, в том числе, для функционирования ЦТК [10]. Однако в этих условиях $\alpha$-кетоглутаратдегидрогеназный комплекс может производить сукцинил-КоА, используя НАД ${ }^{+}$, который образуется в результате превращения оксалацетата в малат (см. схему обращения цикла Кребса в статье Фонсеки), а также генерируется митохондриальными ферментами из группы диафораз [6, 11]. Далее сукцинил-КоА-лигаза катализирует реакцию, в которой из сукцинил-КоА и АДФ (или ГДФ) образуется АТФ (ГТФ), сукцинат и KoASH (так называемое субстратное фосфорилирование). Данный процесс частично компенсирует торможение окислительного фосфорилирования, обеспечивая потребности митохондрии в АТФ в условиях гипоксии $[6,11]$.

Вышеуказанные предположения отчасти гипотетичны, однако важно подчеркнуть, что к настоящему времени общепринятым стало понятие того, что структура и функционирование цикла Кребса не являются жестко запрограммированными, но могут существенно модулироваться для приспособления к меняющимся метаболическим потребностям.

В организме животных и человека появились дополнительные сукцинат-зависимые механизмы приспособления к стрессу. Сукцинат участвует в ответе на гипоксическое воздействие путем активации GPR91, чему и посвящена статья де Кастро Фонсеки. Но не менее важным механизмом является стабилизация сукцинатом фактора, индуцируемого гипоксией (HIF).

HIF - гетеродимер, состоящий из субъединиц $\mathrm{HIF} \alpha$ (существуют изоформы HIF-1 $\alpha,-2 \alpha$ и $-3 \alpha$, несколько различающиеся по структуре и функциям) и HIF $\beta[12,13]$. В условиях нормоксии HIF $\alpha$ быстро инактивируется ферментами из группы пролилгидроксилаз (prolyl hydroxylase domains,
PHDs), из которых в тканях организма человека наиболее широко представлена изоформа PHD2. Гидроксилирование $\mathrm{HIF} \alpha$ требует присутствия кислорода и $\alpha$-кетоглутарата; при этом происходит образование $\mathrm{CO}_{2}$ и сукцината. Гидроксилированный HIF $\alpha$ связывается с убиквитиновым комплексом фон Гиппеля-Линдау (pVHL-E3убиквитинлигаза) и далее подвергается протеасомальной деградации [12-14].

При недостатке кислорода замедляется захват $\mathrm{HIF} \alpha$ убиквитинлигазой, в результате чего содержание HIF $\alpha$ в клетке возрастает. HIF $\alpha$ поступает в ядро клетки, где связывается с субъединицей HIF $\beta$. Данный димер активирует целый ряд (по некоторым данным, более тысячи) генов, ответственных за продукцию сосудистых факторов роста (VEGF) и ангиогенез, метаболизм глюкозы, пролиферацию эритроцитов и других клеток [6, 8]. Так, HIF активирует гликолиз, индуцируя гены, кодирующие транспортеры глюкозы (GLUT1, GLUT3), апрегулирует лактатдегидрогеназу A, которая конвертирует пируват в лактат и регенерирует $\mathrm{NAD}^{+}$, необходимый для гликолиза, а также монокарбоксилатный транспортер 4 (MCT4), переносящий лактат за пределы клетки [14, 15].

HIF ингибирует пируватдегидрогеназу, замедляя тем самым конверсию пирувата в ацетил-КоА и увеличивая шунтирование пирувата из клетки. Вследствие этого происходит подавление цикла Кребса и окислительного фосфорилирования. [14]. Снижение интенсивности митохондриального дыхания понижает потребности митохондрий в кислороде и уменьшает образование активных форм кислорода (АФК), которые могут оказывать повреждающее действие на клеточные структуры.

Активация HIF приводит к торможению липолиза и, соответственно, к ограничению утилизации свободных жирных кислот [14]. При гликолизе на синтез одной молекулы АТФ расходуется на 3540\% меньше кислорода, чем при окислении жирных кислот, поэтому в условиях гипоксии предпочтительным является процесс окисления глюкозы $[16,17]$. Аналогичный механизм действия имеет известный препарат триметазидин из группы p-FOXингибиторов, который тормозит бета-окисление жирных кислот в митохондриях, блокируя фермент 3-кетоацил-КоА-тиолазу, что сопровождается относительным возрастанием роли гликолиза в миокарде с соответственным увеличением эффективности синтеза АТФ и одновременным уменьшением образования свободных радикалов [3, 18, 19].

HIF увеличивает экспрессию цитохрома $b$ (DcytB), восстанавливающего трехвалентное же- 
лезо до двухвалентного, и транспортера дивалентных ионов металлов (DMT1), усиливая тем самым всасывание железа в кишечнике [20, 21].

Кофактором PHD2 является $\alpha$-кетоглутарат. В ходе реакции гидроксилирования $\mathrm{HIF} \alpha$ происходит, как было указано выше, образование сукцината в результате окисления и декарбоксилирования $\alpha$-кетоглутарата. Сукцинат по механизму обратной связи ингибирует пролилгидроксилазы, способствуя стабилизации HIF [12]. Таким образом, повышение концентрации сукцината в тканях, в том числе за счет его экзогенного поступления, приводит к развертыванию всех многочисленных эффектов, обусловленных HIF (рисунок). Подтверждением этого могут послужить полученные нами результаты. Так, во всех проведенных исследованиях, посвященных изучению эффектов применения сукцинатсодержащих диализирующих растворов (СДР), было отмечено достоверное, хотя и умеренное, повышение концентрации гемоглобина в крови пациентов, получающих лечение хроническим гемодиализом, а также гипохолестеринемический эффект [1-4]. Имеющий большое клиническое значение для этой группы пациентов гипонатриемический эффект СДР, как нам представляется, также может быть HIF-опосредованным. В организме человека значительные количества натрия депониру- ются в соединительной ткани (преимущественно, в интерстиции кожи) путем связывания с глюкозоаминогликанами [22-24].

Стабилизация сукцинатом HIF приводит к активации ангиогенеза, в том числе, новообразованию лимфатических капилляров в интерстиции, что способствует выведению натрия из интерстициального депо в кровоток и улучшает эквилибрацию натрия в крови и межклеточной жидкости во время сеанса гемодиализа [4, 23, 24].

Помимо этого, применение СДР можно рассматривать как своего рода гипоксическое или, точнее, псевдогипоксическое прекондиционирование. Около 30 лет назад было показано, что короткие повторные эпизоды гипоксии уменьшают клеточный ответ на недостаток кислорода и оказывают протективное в отношении последующих эпизодов ишемии действие на миокард и головной мозг $[25,26]$. Различные методики гипоксического прекондиционирования (гипобарическое, нормобарическое, гипоксическое) широко используются, в частности, в спортивной медицине [27]. Данный феномен хорошо укладывается в рамки одного из базовых принципов физиологии - гормезиса, под которым понимают стимулирующее влияние малых доз различных стрессорных факторов при наличии ингибирующего эффекта в высоких дозах

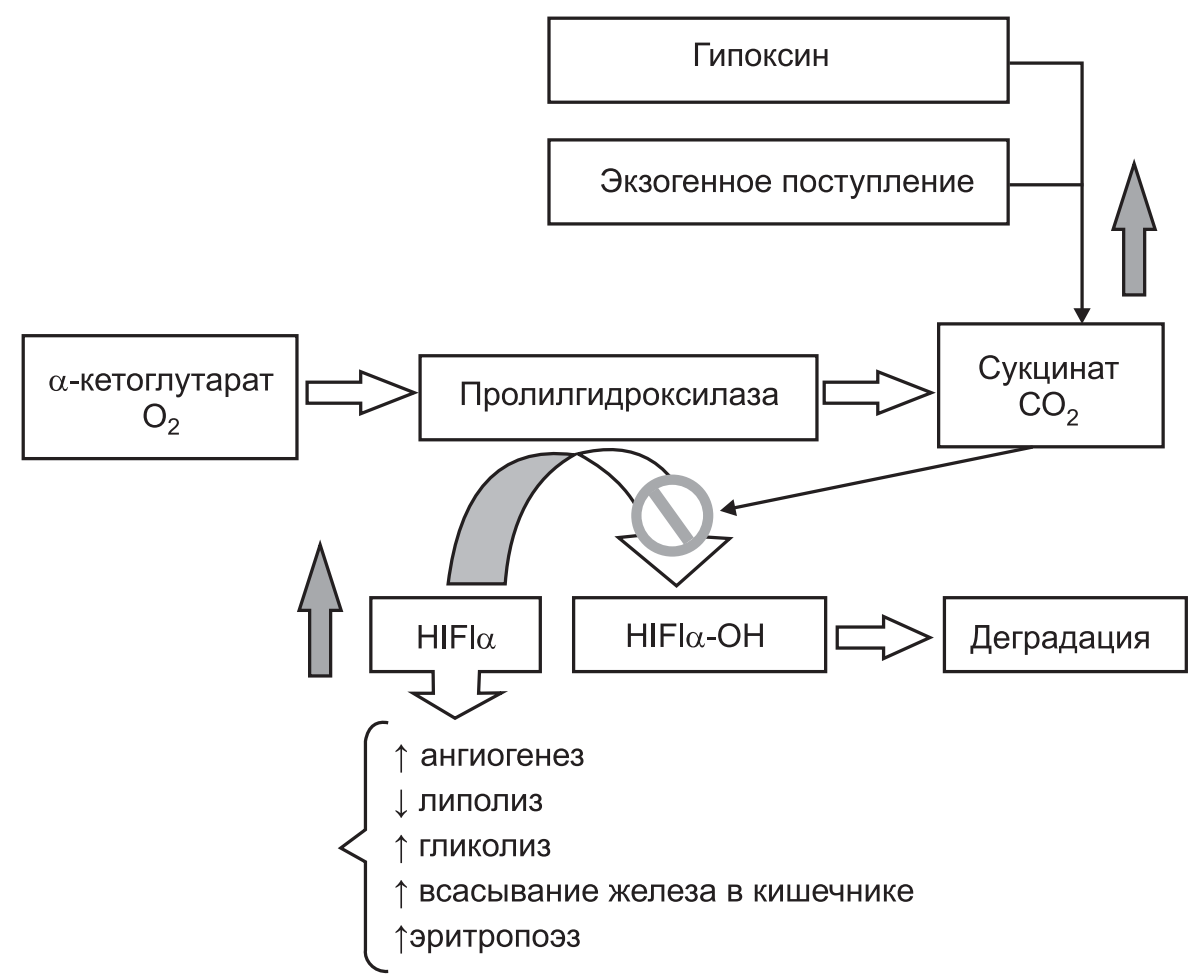

Схема взаимодействия сукцината и фактора, индуцируемого гипоксией (HIF). Повышение содержания сукцината в цитоплазме, вызванное гипоксией или экзогенным поступлением сукцината, по механизму обратной связи ингибирует пролилгидроксилазы, препятствуя гидроксилированию и последующей деградации HIF. Стабилизация и накопление HIF приводят к развертыванию указанных на рисунке эффектов. 
[28]. Наиболее известный пример гормезиса - позитивное действие малых доз радиации (радоновые ванны и проч.), в то время как высокие дозы вызывают лучевую болезнь. Одним из ключевых механизмов реализации протективного действия гипоксического прекондиционирования считают активацию HIF. При этом существует предположение, что ответ на длительную гипоксию отличается от такового при кратковременной преходящей гипоксии, поскольку в этих двух ситуациях индуцируются разные наборы генов [29].

Таким образом, необходимыми условиями для проявления защитного эффекта являются кратковременность и повторность эпизодов гипоксии, т.е. чередование состояний гипоксии и реоксигенации, а также надлежащая (не низкая и не чрезмерная) интенсивность воздействия [27]. Эти условия соблюдаются при использовании СДР, когда больной подвергается воздействию умеренных доз сукцината (по нашим данным, за сеанс гемодиализа в кровоток поступает в среднем около 1 г сукцината [5]) три раза в неделю по 4-5 ч во время сеансов гемодиализа. Феномен гипоксического прекондиционирования может дополнять описанные нами ранее механизмы противоишемического (уменьшение суммарной длительности эпизодов депрессии сегмента ST по данным 24-часового кардиомониторирования) и антиаритмического действия СДР $[1,2,5]$.

Необходимо также помнить, что одни и те же молекулярные механизмы могут обусловливать как защитные, так и патогенные эффекты. Так, в настоящее время продолжаются клинические исследования нового класса противоанемических лекарственных препаратов (роксадустат, дапродустат, молидустат и др.), механизм действия которых основан на стабилизации HIF [8]. Уже полученные данные не только показали эффективность этих препаратов в отношении коррекции анемии, но и продемонстрировали ряд прогнозируемых преимуществ, таких как улучшение биодоступности железа и положительное влияние на липидный профиль, перед используемыми с этой целью другими медикаментозными средствами $[13,30$, 31]. В то же самое время проходят испытания ингибиторы HIF уже в качестве противоопухолевых препаратов, поскольку HIF-зависимые механизмы принимают непосредственное участие в процесcax канцерогенеза и метастазирования злокачественных опухолей $[32,33]$.

Молекулярные механизмы, лежащие в основе гипоксического прекондиционирования, во многом соответствуют имеющим место при синдро- ме обструктивного ночного апноэ, который четко ассоциирован с развитием сердечно-сосудистой патологии [29, 34].

Сукцинат, накопившийся в клетке во время эпизода ишемии, в условиях реоксигенации после восстановления перфузии активно окисляется с образованием большого количества АФК. «Взрывная» продукция АФК митохондриями считается одним из основных патогенных факторов ишемическо-реперфузионного повреждения [35]. Негативные последствия оксидативного стресса хорошо известны, однако само по себе повышение образования АФК не является его синонимом. В соответствии с современными представлениями, оксидативный стресс - не просто отклонение от нейтрального баланса между продукцией и утилизацией АФК. Концепция оксидативного стресса на сегодняшний день обязательно включает в себя дополнительные сведения о преимущественной локализации АФК (субклеточной или тканевой), химической природе АФК (свободнорадикальные или нерадикальные, такие как перекись водорода, гипохлорит, пероксинитрит и др.), данные о кинетике образования и деградации АФК [36]. Состояние восстановительного стресса, могущее возникать в том числе и при гипоксии, не менее (а возможно, и более) опасно для организма, чем оксидативный стресс [37]. АФК являются естественными и необходимыми сигнальными метаболитами организма [38]. К примеру, показано, что при гипоксии митохондрии - один из главных источников АФК в организме - образуют кластер вблизи ядра; при этом содержание АФК в ядре увеличивается, что является необходимым условием для связывания HIF1 $\alpha$ с VEGF-промоутером и экспрессии VEGF [39]. Физические упражнения являются зачастую недооцениваемым, но доказанно эффективным методом профилактики и лечения десятков болезней [40]. Так, регулярные физические нагрузки снижают резистентность к инсулину и увеличивают продолжительность жизни больных с сахарным диабетом 2-го типа, несмотря на то, что при физических упражнениях происходит усиленная выработка АФК [28]. Более того, назначение антиоксидантов ослабляет или даже полностью исключает этот протективный эффект [41]. Таким образом, кратковременное увеличение продукции АФК за счет окисления накопившегося во время эпизода ишемии сукцината может являться не только неизбежной платой за выживание клеток в условиях гипоксии, но и адаптационным механизмом.

Сукцинат (точнее, сукцинил-КоА) принимает активное участие в процессах посттрансляцион- 
ной модификации белков (реакции сукцинилирования). Сукцинилирование нужно отличать от сукцинирования, т.е. образования 2-сукциноцистеина из цистеина и фумарата. Образующаяся при этом тиоэфирная связь является весьма стабильной в отличие от обратимых реакций сукцинилирования и ацетилирования по лизиновым остаткам белков [42]. Биологические и клинические эффекты сукцинилирования протеинов находятся в стадии изучения. Имеющиеся на данный момент свидетельства неоднозначны: с одной стороны, высокий уровень сукцинилирования обнаружен в раковых клетках $[6,43]$, с другой выявлено гипосукцинилирование протеинов в различных тканях головного мозга при болезни Альцгеймера [44]. По-видимому, можно провести аналогию с более хорошо изученным феноменом ацетилирования белков, за счет которого регулируется множество процессов в клетках, в том числе, экспрессия генов, и сукцинилирование также является важным регуляторным механизмом. Об этом свидетельствует, например, то, что уровень сукцинилирования, также как и ацетилирования, контролирует фермент из группы гистоновых деацетилаз - сиртуин 5, а также широкая распространенность сукцинилирования: по имеющимся данным, сукцинилировано около $25 \%$ митохондриальных белков в клетках животных [45].

Таким образом, сукцинат - не только лиганд GPR91. Сукцинат-зависимый ответ на гипоксию реализуется с помощью целого ряда биохимических процессов. Сукцинат - стабилизатор фактора, индуцируемого гипоксией. Сукцинат - субстрат сукцинатдегидрогеназы, одного из ключевых ферментов цикла Кребса и компонента дыхательной цепи митохондрий, и продукт реакции субстратного фосфорилирования. Тем самым сукцинат является непосредственным участником процессов синтеза АТФ, продукции активных форм кислорода, ана- и катаплероза. Множественность биологических функций и общность молекулярных механизмов, обеспечивающих положительные и негативные эффекты сукцината, обусловливает необходимость учета возможных неблагоприятных последствий при использовании сукцината в качестве лекарственного средства. Краеугольный камень успешного медикаментозного лечения - дать нужное лекарство в нужной дозе в нужное время. Это в полной мере относится и к сукцинатсодержащим растворам для гемодиализа, причем в последнем случае количество сукцината, поступающее в организм за конкретный промежуток времени, определяется главным образом фактором диффузии через диализную мембрану.

\section{БИБЛИОГРАФИЧЕСКИЙ СПИСОК}

1. Смирнов АВ, Нестерова ОБ, Голубев РВ и др. Кардиопротективные эффекты сукцинатсодержащего диализирующего раствора. Нефрология 2012; 16(2): 69-78 [Smirnov AV, Nesterova OB, Golubev RV i dr. Kardioprotektivnye e'ffekty sukcinatsoderzhashhego dializiruyushhego rastvora. Nefrologiya 2012; 16(2): 69-78]

2. Смирнов АВ, Нестерова ОБ, Суглобова ЕД и др. Клинико-лабораторная оценка эффективности лечения больных с терминальной стадией почечной недостаточности с использованием хронического гемодиализа и ацидосукцината. Тер Apx 2013; 85(1): 69-75 [Smirnov AV, Nesterova OB, Suglobova ED i dr. Kliniko-laboratornaya ocenka e'ffektivnosti lecheniya bol'nyh s terminal'noj stadiej pochechnoj nedostatochnosti s ispol'zovaniem hronicheskogo gemodializa i acidosukcinata. Ter Arh 2013; 85(1): 69-75]

3. Смирнов АВ, Нестерова ОБ, Голубев РВ. Янтарная кислота и её применение в медицине. Часть II. Применение янтарной кислоты в медицине. Нефрология 2014; 18(4): 12-24 [Smirnov AV, Nesterova OB, Golubev RV. Yantarnaya kislota i eyo primenenie v medicine. Chast' II. Primenenie yantarnoj kisloty v medicine. Nefrologiya 2014; 18(4): 12-24]

4. Смирнов АВ, Голубев РВ, Васильев АН и др. Гемодинамические эффекты содержащего сукцинат диализирующего раствора. Тер Арх 2015; 87(6): 56-61. doi: 10.17116/ terarkh201587656-61 [Smirnov AV, Golubev RV, Vasil'ev AN i dr. Gemodinamicheskie e'ffekty soderzhashhego sukcinat dializiruyushhego rastvora. Ter Arh 2015; 87(6): 56-61. doi: 10.17116/ terarkh201587656-61]

5. Смирнов АВ, Нестерова ОБ, Голубев РВ, Лазеба ВА. Сукцинатсодержащие диализирующие растворы в практике гемодиализа. Левша, СПб., 2014; 73-82 [Smirnov AV, Nesterova $\mathrm{OB}$, Golubev RV, Lazeba VA. Sukcinatsoderzhashhie dializiruyushhie rastvory v praktike gemodializa. Levsha, SPb, 2014; 73-82]

6. Benit P, Letouze E, Rak M et al. Unsuspected task for an old team: succinate, fumarate and other Krebs cycle acids in metabolic remodeling. Biochim Biophys Acta 2014; 1837(8): 1330-1337. doi: 10.1016/j.bbabio.2014.03.013

7. Glissen J, Jouret F, Pirotte B, Hanson J. Insight into SUCNR1 (GPR91) structure and function. Pharmacol Ther 2016; doi: 10.1016/j.pharmthera.2016.01.008 [Epub ahead of print]

8. Tretter L, Patocs A, Chinopoulos C. Succinate, an intermediate in metabolism, signal transduction, ROS, hypoxia, and tumorigenesis. BBA - Bioenergetics 2016; doi: 10.1016/j.bbabio.2016.03.012 [Epub ahead of print]

9. Antonio C, Papke C, Rocha M et al. Regulation of primary metabolism in response to low oxygen availability as revealed by carbon and nitrogen isotope redistribution. Plant Physiol 2016: 170(1): 43-56. doi: 10.1104/pp. 15.00266

10. Titov D, Cracan V, Goodman R et al. Complementation of mitochondrial electron transport chain by manipulation of the $\mathrm{NAD}^{+} / \mathrm{NADH}$ ratio. Science 2016; 352(6282): 231-235. doi: 10.1126/science.aad4017

11. Kiss G, Konrad C, Pour-Ghaz I et al. Mitochondrial diaphorases as $\mathrm{NAD}^{+}$donors to segments of the citric acid cycle that support substrate-level phosphorylation yielding ATP during respiratory inhibition. FASEB J 2014; 28(4): 1682-1697. doi: 10.1096/fj. 13-243030

12. Qutub A, Popel A. Three autocrine feedback loops determine HIF1 $\alpha$ expression in chronic hypoxia. Biochim Biophys Acta 2007; 1773(10): 1511-1525. doi: 10.1016/j.bbamcr.2007.07.004

13. Schmid H, Jelkmann W. Investigational therapies for renal disease-induced anemia. Expert Opin Investig Drugs 2016; doi: 10.1080/13543784.2016.1182981 [Epub ahead of print]

14. Schonenberger $M$, Kovacs W. Hypoxia signaling pathways: modulators of oxygen-related organelles. Front Cell Dev Biol 2015; 3: 42. doi: $10.3389 /$ fcell.2015.00042

15. Semenza G. Hypoxia-inducible factors in physiology and medicine. Cell 2012; 148(3): 399-408. doi: 10.1016/j. cell.2012.01.021

16. Stanley WC, Recchia FA, Lopaschuk GD. Myocardial substrate metabolism in the normal and failing heart. Physiol Rev 2005; 85(3): 1093-1129. doi: 10.1152/physrev.00006.2004 
17. Ingwall JS. Energy metabolism in heart failure and remodeling. Cardiovasc Res 2009; 81(3): 412-419. doi: 10.1093/ cvr/cvn301

18. Тугушева ФА, Куликова АИ, Коношкова РЛ. О влиянии предуктала-20 на ишемию миокарда и показатели липопероксидации в крови больных с хронической почечной недостаточностью, получающих регулярный гемодиализ. Нефрология 1997; 1(2): 73-78 [Tugusheva FA, Kulikova AI, Konoshkova RL. O vliyanii preduktala-20 na ishemiyu miokarda pokazateli lipoperoksidacii v krovi bol'nyh s hronicheskoj pochechnoj nedostatochnost'yu, poluchayushhih regulyarnyj gemodializ. Nefrologiya 1997; 1(2): 73-78]

19. Zhou X, Chen J. Is treatment with trimetazidine beneficial in patients with chronic heart failure? PLOS One 2014, 9(5), e94660. doi: 10.1371/journal.pone.0094660

20. Anderson $E$, Xue $X$, Shah $Y$. Intestinal hypoxia-inducible factor-2 $\alpha$ (HIF-2 $\alpha$ ) is critical for efficient erythropoiesis. $J$ Biol Chem 2011; 286(22): 19533-19540. doi: 10.1074/jbc. M111.238667

21. Barrett TD, Palomino HL, Brondstetter TI et al. Prolyl hydroxylase inhibition corrects functional iron deficiency and inflammation-induced anaemia in rats. $\mathrm{Br} J$ Pharmacol 2015 172(16): 4078-4088. doi: 10.1111/bph.13188

22. Titze J, Machnic A. Sodium sensing in the interstitium and relationship to hypertension. Curr Opin Nephrol Hypertens 2010; 19(4): 385-392. doi: 10.1097/MNH.0b013e32833aeb3b

23. Titze J, Dahlmann A, Lerchl K et al. Spooky sodium balance. Kidney Int 2013; 85(4): 759-767. doi: 10.1038/ki.2013.367

24. Titze J, Muller DN, Luft FC. Taking another "look" at sodium. Can J Cardiol 2014; 30(5): 473-475. doi: 10.1016/j. cjca.2014.02.006

25. Murry C, Jennings R, Reimer K. Preconditioning with ischemia: a delay of lethal cell injury in ischemic myocardium. Circulation 1986; 74(5): 1124-1136. doi: 10.1161/01.CIR.74.5.1124

26. Kitagawa K, Matsumoto M, Tagaya M. et al. "Ischemic tolerance» phenomenon found in the brain. Brain Res 1990; 528(1): 21-24. doi: 10.1016/0006-8993(90)90189-I

27. Rybnikova E, Samoilov M. Cuttent insights into the molecular mechanisms of hypoxic pre- and postconditioning using hypobaric hypoxia. Front Neurosci 2015; 9: 388. doi: 10.3389/ fnins.2015.00388

28. Calabrese V, Cornelius C, Dinkova-Kostova A et al. Cellular stress responses, the hormesis paradigm, and vitagenes: novel targets for therapeutic intervention in neurodegenerative disorders. Antioxid Redox Signal 2010; 13(11): 1763-1811. doi: 10.1089/ars.2009.3074

29. Samaja M, Milano G. Editorial - Hypoxia and reoxygenation: from basic science to bedside. Front Pediatr 2015; 3: 86 doi:10.3389/fped.2015.00086

30. Besarab A, Provenzano R, Hertel J et al. Randomised placebo-controlled dose-ranging and pharmacodynamics study of roxadustat (FG-4592) to treat anemia in nondialysis-dependent chronic kidney disease (NDD-CKD) patients. Neprol Dial Transplant 2015; 30(10): 1665-1673. doi: 10.1093/ndt/gfv302

31. Provenzano R, Besarab A, Wright S et al. Roxadustat (FG-4592) versus epoetin alfa for anemia in patients receiving maintenance hemodialysis: a phase 2, randomized, 6- to 19-week, open-label, active-comparator, dose-ranging, safety and exploratory efficacy study. AJKD 2016; doi: 10.1053/j.ajkd.2015.12.020 [Epub ahead of print]

32. Lee K, Kim HM. A novel approach to cancer therapy using PX-478 as a HIF-1 $\alpha$ inhibitor. Arch Pharm Res 2011; 34(10): 1583-1585. doi: 10.1007/s12272-011-1021-3

33. Hu Y, Liu J, Huang $\mathrm{H}$. Recent agents targeting HIF-1 $\alpha$ for cancer therapy. J Cell Biochem 2013; 114(3): 498-509. doi: 10.1002/jcb.24390

34. Ali S, Oni E, Waraich $\mathrm{H}$ et al. Systematic review on noninvasive assessment of subclinical cardiovascular disease in obstructive sleep apnea: new kid on the block! Sleep Med Rev 2014; 18(5): 379-381. doi: 10.1016/j.smrv.2014.01.004

35. Chouchani E, Pell V, Gaude E et al. Ischaemic accumulation of succinate controls reperfusion injury through mitochondrial ROS. Nature 2014; 515(7527): 431-435. doi: 10.1038/ nature13909
36. Schmidt H, Stocker R, Vollbracht $\mathrm{C}$ et al. Antioxidants in translational medicine. Antioxid Redox Signal 2015; 23(14): 11301143. doi: 10.1089/ars.2015.6393

37. Zhang H, Limphong P, Pieper J et al. Glutathione-dependent reductive stress triggers mitochondrial oxidation and cytotoxicity. FASEB J 2012; 26(4): 1442-1451. doi: 10.1096/fj.11-199869

38. Veal E, Day A, Morgan B. Hydrogen peroxide sensing and signaling. Mol Cell Rev 2007; 26(1): 1-14. doi: 10.1016/j. molcel.2007.03.016

39. Al-Mehdi A-B, Pastukh V, Swiger B et al. Perinuclear mitochondrial clustering creates an oxidant-reach nuclear domain required for hypoxia-induced transcription. Sci Signal 2012; 5(231): ra47. doi: 10.1126/scisignal.2002712

40. Powers S, Smuder A, Kavazis A, Quindry J. Mechanisms of exercise-induced cardioprotection. Physiology(Bethesda) 2014; 29(1):27-38. doi: 10.1152/physiol.00030.2013

41. Ristow M, Zarse K, Oberbach A et al. Antioxidants prevent health-promoting effects of physical exercise in humans. Proc Natl Acad Sci USA 2009; 106(21): 8665-8670. doi: 10.1073/ pnas.0903485106

42. Merkley E, Metz T, Smith R. The succinated proteome. Mass Spectrom Rev2014; 33(2): 98-109. doi: 10.1002/mas.21382

43. Kuo C-Y, Cheng C-T, Hou P et al. HIF-1-alpha links mitochondrial perturbation to the dynamic acquisition of breast cancer tumorigenicity. Oncotarget 2016; doi: 10.18632/oncotarget.8570 [Epub ahead of print]

44. Gibson G, Xu H, Chen H-L et al. Alpha-ketoglutarate dehydrogenase complex-dependent succinilation of proteins in neurons and neuronal cell lines. J Neurochem 2015; 134(1): 86 96. doi: 10.1111/jnc. 13096

45. McKenna M, Rae C. A new role for $\alpha$-ketoglutarate dehydrogenase complex: regulating metabolism through posttranslational modification of other enzymes. J Neurochem 2015; 134(1): 3-6. doi: 10.1111/jnc. 13150

\section{Сведения об авторах:}

Голубев Роман Владимирович, канд. мед. наук

197022, Россия, Санкт-Петербург, ул. Л. Толстого, д. 17, корп. 54. Первый Санкт-Петербургский государственный медицинский университет им. акад. И.П. Павлова, Научноисследовательский институт нефрологии, лаборатория почечной недостаточности, зав. лабораторией. Тел. (812) 33869-14; E-mail: romvladgol@gmail.com

Roman V. Golubev, PhD

Affiliations: 197022, Russia, St-Petersburg, L. Tolstoy st., 17, build. 54, First Pavlov St-Petersburg State Medical University, Research Institute of Nephrology, Laboratory of Renal Insufficiency, head. Phone: (812) 338-69-14; E-mail: romvladgol@gmail.com

Проф. Смирнов Алексей Владимирович

197022, Россия, Санкт-Петербург, ул. Л. Толстого, д. 17, корп. 54. Первый Санкт-Петербургский государственный медицинский университет им. акад. И.П. Павлова, Научноисследовательский институт нефрологии, директор. Тел.: (812) 338-69-01; E-mail: smirnov@nephrolog.ru

Prof. Alexey V. Smirnov MD, PhD, DMedSci.

Affiliations: 197022, Russia, St-Petersburg, L. Tolstoy st., 17, build. 54, First Pavlov St-Petersburg State Medical University, Research Institute of Nephrology, director. Phone: (812) 338-6901; E-mail: smirnov@nephrolog.ru

Авторы заявляют об отсутствии конфликта uнтересов. 